\title{
Myoepithelial Cells: Their Origin and Function in Lacrimal Gland Morphogenesis, Homeostasis, and Repair
}

\author{
Helen P. Makarenkova ${ }^{1} \cdot$ Darlene A. Dartt $^{2}$
}

Published online: 10 July 2015

(C) Springer International Publishing AG 2015

\begin{abstract}
Lacrimal gland (LG) is an exocrine tubuloacinar gland that secretes the aqueous layer of the tear film. LG epithelium is composed of ductal, acinar, and myoepithelial cells (MECs) bordering the basal lamina and separating the epithelial layer from the extracellular matrix. Mature MECs have contractile ability and morphologically resemble smooth muscle cells; however, they exhibit features typical for epithelial cells, such as the presence of specific cytokeratin filaments. Increasing evidence supports the assertion that myoepithelial cells (MECs) play key roles in the lacrimal gland development, homeostasis, and stabilizing the normal structure and polarity of LG secretory acini. MECs take part in the formation of extracellular matrix gland and participate in signal exchange between epithelium and stroma. MECs have a high level of plasticity and are able to differentiate into several cell lineages. Here, we provide a review on some of the MEC characteristics and their role in LG morphogenesis, maintenance, and repair.
\end{abstract}

This article is part of the Topical Collection on Molecular Biology of Adult Stem Cells

Electronic supplementary material The online version of this article (doi:10.1007/s40610-015-0020-4) contains supplementary material, which is available to authorized users.

Helen P. Makarenkova

hmakarenk@scripps.edu

1 Department of Cell and Molecular Biology, The Scripps Research Institute, 10550 North Torrey Pines Road, La Jolla, CA 92037, USA

2 Schepens Eye Research Institute/Massachusetts Eye and Ear, Department of Ophthalmology, Harvard Medical School, Boston, MA, USA
Keywords Lacrimal gland $\cdot$ Myoepithelial cells $\cdot$ Stem · Progenitor cells $\cdot$ Morphogenesis $\cdot$ Regeneration $\cdot$ Smooth muscle actin · Fibroblast growth factor · Epithelium . Mesenchyme $\cdot$ Branching

\section{Introduction}

Myoepithelial cells (MECs) are found in multiple glandular organs such as the lacrimal, salivary, harderian, sweat, prostate, and mammary glands. These cells surround glandular secretory epithelium; express $\alpha$-smooth muscle actin (SMA), a marker for MECs; and can contract thereby modulating secretory function of these exocrine glands [1-7]. MEC contractile capacity, controlled by hormonal and neural mechanisms, plays an important role in propulsion of secretion. In the lacrimal gland (LG) and other exocrine glands, MECs synthesize the basement membrane and form a functional network around the acinar and ductal cells separating them from the basement membrane and the mesenchymal stromal cells [8-10]. Furthermore, it has been proposed that MECs maintain glandular structural integrity and transport metabolites to secretory cells. Although the significance of MECs is still speculative, some new recent studies have suggested the importance of MECs for exocrine gland structural integrity [11, 12]. In spite of the proposed importance of MECs for LG function, MECs in the LG are lesser studied than other exocrine glands. Here, we provide a review on the role of MECs in LG morphogenesis, maintenance, and repair.

\section{Lacrimal Gland Structure and Development}

LGs are paired exocrine tubuloacinar glands that secrete the aqueous layer of the tear film. The mature LG is made up of many lobules separated by connective tissue. Each lobule 
contains numerous secretory acini. The secretory function of the LG completely depends on development and differentiation of LG epithelial cell types (Fig. 1a). The LG epithelial tree is composed of three major cell types: ductal, acinar, and myoepithelial cells (Fig. 1). Acinar cells secrete the primary LG fluid (Fig. 1b), and ductal cells (Fig. 1c) modify the electrolyte composition of the primary LG fluid before it exits the ducts and flows onto the ocular surface. MECs have a contractile function that, perhaps as in the salivary and mammary glands, helps expel the secreted fluid (Fig. 1d). The LG is innervated by parasympathetic and sympathetic nerves that control LG protein, electrolyte, and water secretion by the three cell types [7, 13].

The development of the human LG has been studied by numerous authors [14-17]. Human LG morphogenesis could be divided into three stages: (1) the presumptive glandular stage, O'Rahilly's stages 19-20, characterized by a thickening of the superior fornix epithelium of the conjunctiva; (2) the bud stage, O'Rahilly's stage 21, characterized by the appearance of the primary LG bud; and (3) the glandular maturity stage, O'Rahilly's stages 22-23, weeks 9-16, when the LG develops into a branched acinar/ductal structure [14].

Mouse LG development shares some common features with salivary gland development [18-22]. More specifically, branching of lacrimal and salivary glands is controlled by fibroblast growth factor (FGF) 10 (expressed in mesenchyme) and FGFR2b (expressed in the epithelium). Developing LG consists of an epithelial tree branched within the stromal tissue composed by the extracellular matrix and different types of cells of mesenchymal origin [21]. LG development is initiated at embryonic day 13.5 (E13.5), as a single bud invagination of the conjunctival epithelium at the temporal edge of the eye. At E15.5, the LG bud produces a tubular structure with a thickening at the tip, extended caudally in the subcutaneous tissue between skin and cranial bones and underneath the supraorbital branch of the stapedial artery [20,21, 23]. Branching in the developing gland appears around E16.5. By E19.5, the LG contains well-branched intra- and exorbital lobes [21]. In mice, the LG continues to differentiate during postnatal development and maturation is complete around $\mathrm{P} 30$.

The appearance and differentiation of MECs during LG development has limited documentation. In 1995, Wang and co-authors [8] described MEC differentiation in LG postnatal development using immunostaining for SMA and phalloidin staining. At P0, when LG rudimentary buds still do not have a clear lumen nor secretory granules, these authors did not detect cells positive for SMA that is MECs. However, at P3 with the appearance of a lumen in some of the epithelial rudiments, SMA-positive cells were already found in the peripheral region of the LG buds. These immature MECs were almost round and had a few processes. Starting from P7 when epithelial cells differentiated to polarized secretory cells, many MECs stained for F-actin (indicated by phalloidin staining)
[8]. Most MECs at this stage had longer processes, but still did not have contact with each other. At 4-8 weeks after birth, MECs increased in size, and had 4-6 processes that extended in all directions and often interacted with each other [8].

The Wang study [8] suggests that (1) myoepithelial cell progenitors (MECPs) probably exist early during LG embryonic development, but do not express SMA and (2) MECPs differentiation starts later at early stages of postnatal development. However, it is also possible that low expression of SMA within small MECPs would be difficult to detect on paraffin sections due to low sensitivity of this type of immunostaining. Unfortunately, there are no later studies on LG MECP/MEC cell specification, proliferation, and differentiation. In view of the central role played by MECPs/MECs in formation of various LG neoplasms [24-27] and the recently reported plasticity of MECs in adult LG [28••], the further identification and analysis of these cells in the normal and diseased LG is important.

\section{MEC Localization, Morphology, and MEC-Specific Markers}

MECs cannot be easily visualized on histological sections (Fig. 2a). In electron microscopic studies of canine LGs, MECs are visualized as electron dense cells between the basal membrane and secretory epithelium [29]. In some publications, MECs of exorbital LGs and harderian glands were visualized with an alkaline phosphatase reaction [30, 31]. Identification of MEC-specific markers enabled studies on their morphology, function, and behavior in normal and diseased glands [26, 32]. As reported in one of the early publications [32], MECs can function as smooth muscle cells and they may be identified by the presence of myofilament proteins that are related to those of smooth muscle cells. The most reliable common MEC marker is SMA ( $\alpha$-smooth muscle actin) [7, 8, 32, 33] (Table 1, Fig. 2b-e).

In the LG, SMA-positive stellate-shaped cells form a basket-like network around the acini (Fig. 2c-d) $[8,28 \bullet \bullet$, 45]. Typically LG MECs have a small (around 10-15 $\mu \mathrm{m}$ ) cell body and several long (often branched) processes, which cause the MEC to occupy a large area. Due to large size of MEC processes, 5-25 $\mu \mathrm{m}$ sections of LG normally contain only partial cells. To visualize the entire MEC, whole mount preparations and confocal microscopy are necessary (compare Fig. $2 b$ with $c-e)$.

Another specific MEC marker is the thin filament-associated protein calponin [42]. Calponin can bind to actin, calmodulin, troponin $\mathrm{C}$, and tropomyosin and is implicated in the regulation and modulation of smooth muscle contraction [46].

Other MEC markers known to date can be found in other cell types of the LG; however, combinations of these markers with SMA is useful for detection of different subpopulations 
Fig. 1 Lacrimal gland epithelial cell types. The LG epithelium (a) is composed of three major cell types: acinar (b), ductal (c), and myoepithelial (MECs) (d red) cells. Acinar cells synthesize and secrete proteins, water, and electrolytes. Ductal cells modify the secretory fluid by secreting electrolytes and water. Myoepithelial cells (MECs) produce basal membrane proteins and have contractile function

\section{LACRIMAL GLAND EPITHELIUM}

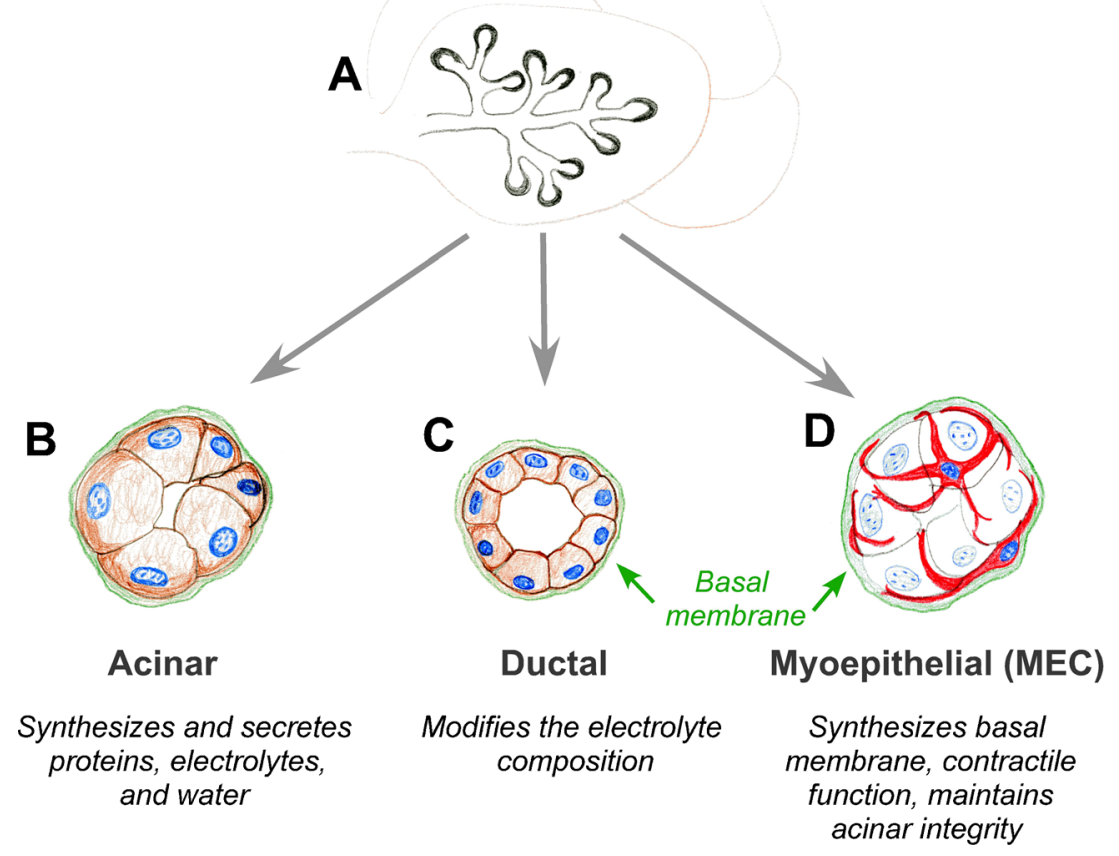

of MECs with diverse functional properties. Thus, similar to other epithelial cells, MECs have keratin-containing intermediate filaments [32]. Most specific to MECs is the expression of cytokeratin-5 (CK5). In human LGs, MECs expressing CK5 and SMA are restricted to acini and intralobular ducts [33]. MECs are also enriched in cytokeratin 14 (CK14) [34]. Expression of $\alpha$-actinin is specific to MECs, at least within the LG [41•] (Table 1). $\alpha$-Actinin is an actin-binding protein with multiple roles in different cell types of multiple tissues. In MECs, as in other non-muscle cells, the $\alpha$-actinin protein was found along microfilament bundles, where it is probably involved in binding actin to the cellular membrane [41•].

Nestin is a class VI intermediate filament protein [47]. Although it is expressed predominantly in neuronal stem cells, it is also found in the proliferating cells of a variety of stem and cancer cells [47-50]. In the LG, some MECs and MECPs are nestin-positive [28••, 36, 37]. MECs are also rich in the expression of muscarinic and purinergic receptors $[41 \bullet, 51]$. Recent analysis of isolated LG MECs in culture showed that similar to acinar cells, they expressed the P2X7, P2Y1, P2Y11, and P2Y13 purinergic receptors [41•] (Table 1).

Although there are not much information about MECspecific transcription factor in the LG, it has been reported that MECs are enriched in the p63 transcription factor (the p53 family of transcription factors), which is encoded by TP63 gene [52]. The N-terminally truncated isoform of p63 $(\Delta \mathrm{Np63})$ is expressed at high levels in many different stem/ progenitor cells [53-55]. Interestingly, in the LG, $\Delta$ Np63 appears to be expressed in subpopulations of the acinar cells and
MECs [28••], while in the mammary gland, p63 is a selective nuclear marker of MECs [56] (Table 1). A mutation in the TP63 gene causes a rare genetic disease, acro-dermato-ungual-lacrimal-tooth (ADULT) syndrome, suggesting that TP63 regulates multiple signaling pathways required for ectodermal organogenesis and differentiation and controls cell growth and survival $[52,54]$. Whether p63 is critical for the maintenance of the progenitor cell populations in LG is still not known.

Another transcription factor that is expressed in MECs is a pared homeobox protein Pax6. In the LG Pax6, expression is restricted to the nuclei of myoepithelial, ductal, and acinar cells $[21,28 \bullet \bullet, 38]$ (Table 1).

Growth factors control LG morphogenesis and therefore MEC differentiation. MECs express CD109, a TGF- $\beta$ co-receptor and a negative regulator of TGF- $\beta$ signaling $[35,57]$. MECs of rat LG also express neurotrophin receptor ( $\mathrm{p} 75)$ [44]. The neurotrophins play critical roles in the development, maintenance, survival, and death of multiple cell types [58-62]. In addition, MECs of the LG express FGF2 [43] (Table 1). Overall, it is clear that MEC signaling networks are not well defined and its analysis requires a combination of molecular and functional approaches.

\section{Myoepithelial Cell Progenitors and Lacrimal Gland Regeneration}

Aqueous deficiency due to lacrimal gland insufficiency or damage is one of the major causes of dry eye. Available 

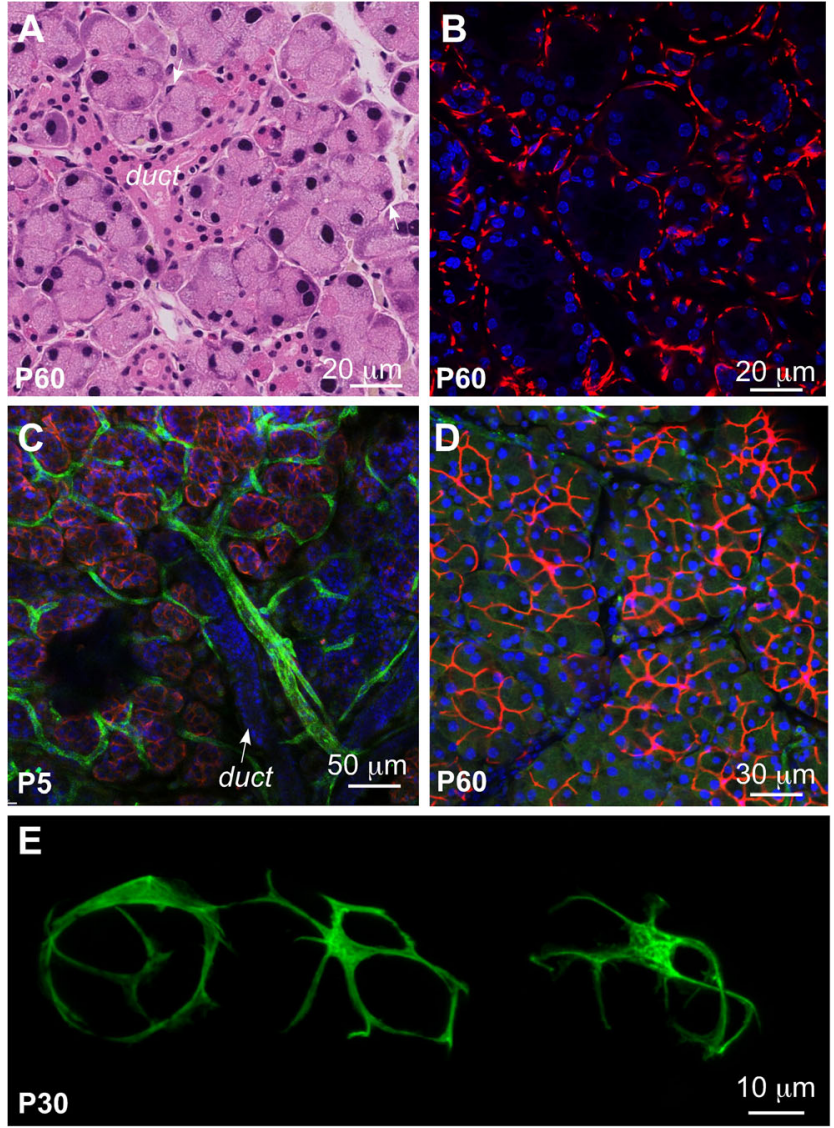

Fig. 2 Lacrimal gland myoepithelial cells. (a) Paraffin section of a mouse LG at postnatal day 60 (P60) stained with hematoxylin/eosin (H\&E), demonstrating the acinar structure of the gland. MECs (white arrows) are hardly visible. (b) Paraffin section of a mouse LG at P60 stained with the antibody to SMA. Due to the large size of adult MECs, only part of cells can be seen (red) (nuclei are stained with DAPI). (c) Whole mount imaging of the mouse LG at P5. MECs (red) are located around differentiating acini, but not around the main duct (white arrow). Blood vessels (green) are stained with the CD31 antibody; the nuclei are stained with DAPI. (d) Whole mount preparation of a mouse LG at P60 demonstrating large MECs (red) with several long processes around the secretory acini. Epithelial cells are stained with the Panx1 antibody (green), nuclei are stained with DAPI. (e) Typical shapes of MECs in adult LGs as visualized with SMA expression. The cells have 4-7 long processes that may also be branched

treatment options such as tear substitutes do not provide sufficient relief in patients with LG dysfunction. A possible longterm solution to treat dry eye could be isolation and transplantation of LG stem/progenitor cells or generation of bioengineered LGs [63]. Both of these approaches propose use of stem/progenitor cells; however, information on LG stem cells being able to restore LG function is very limited. Such information is necessary for the development of new stem cell-based therapeutic approaches.

Evidence to date suggests that the adult LG contains both slow cycling stem cells [64] and faster cycling progenitor cells $[28 \bullet \bullet, 37]$ and that the LG is able to repair itself even after substantial damage [36]. However, the source of stem or progenitor cells for $\mathrm{LG}$ regeneration remains unclear. Adult stem cells are mainly represented by tissue-specific stem cells, also referred to as slow cycling (label retaining) multipotent cells $[65,66]$. In contrast, progenitor cells, early descendants of slow cycling stem cells, proliferate faster and differentiate into one or more cell types within a given tissue [67]. Tissuespecific stem cells are generally believed to differentiate along relatively restricted cell lineages [68-72]. Moreover, it is increasingly apparent that the properties of an adult stem cell depend as much on the niche in which it resides as on its inherent "stemness" [73, 74]. In self-renewing tissues, differentiated cell types are specified through distinct cell lineages. Such lineages may include stem and progenitor (transitamplifying) cells, which give rise to lineage-specific differentiated cells.

Since the LG has only three major cell types: ductal, acinar, and MEC (Fig. 1), there are three opposing concepts on the origin of stem/progenitor cells in the adult LG (Fig. 3). One hypothesis postulates that a single common multipotent (able to form all three cell types) stem cell exists within the adult LG. Upon activation, this LG stem cell is able to give rise to lineage-specific progenitor cells, such as ductal, acinar, and MECs (Fig. 3a). The second hypothesis proposes that each cell lineage contains its own lineage-specific stem/progenitor cells that contribute to the architecture of adult LGs (Fig. 3b). At the same time, one or another lineage-specific stem/ progenitor cells may have different fates during normal LG morphogenesis and repair (Fig. 3b). Thus, the third hypothesis suggests that multipotent stem/progenitor cells may exist in one or another LG cell lineage. Upon LG injury/disease these multipotent stem/progenitor cells can replace all epithelial lineages (Fig. 3b).

Over the last few years, the MEC populations of different glandular tissues including LG have attracted the considerable attention of many researchers due to MEC plasticity and therefore a proposed role in tissue repair. The question of how MECs arise in the LG has also gained increasing interest due to the proposed role for MECs in formation of some LG tumors $[75,76]$. More recent studies indicate that, similarly to other exocrine glands (pancreas, salivary, mammary) [77-80], the LG has a high regenerative potential and is able to repair itself even after substantial damage [81]. These studies suggest that the LG contains resident stem/progenitor cells capable of restoring the $\mathrm{LG}$ function.

MECs retain some proliferative potential in adult uninjured LG and salivary glands, have a high level of plasticity, and may participate in gland regeneration [82, 83]. MECs of parotid glands show a strong increase (up to $23 \%$ ) in their proliferative rate 5 days following gland injury, while proliferation of other epithelial cell types (ductal and acinar) increases much later on days 7-10 after injury [83]. This rapid response of MECs to parotid gland injury suggests that a subpopulation of MECs may contain faster proliferating- 


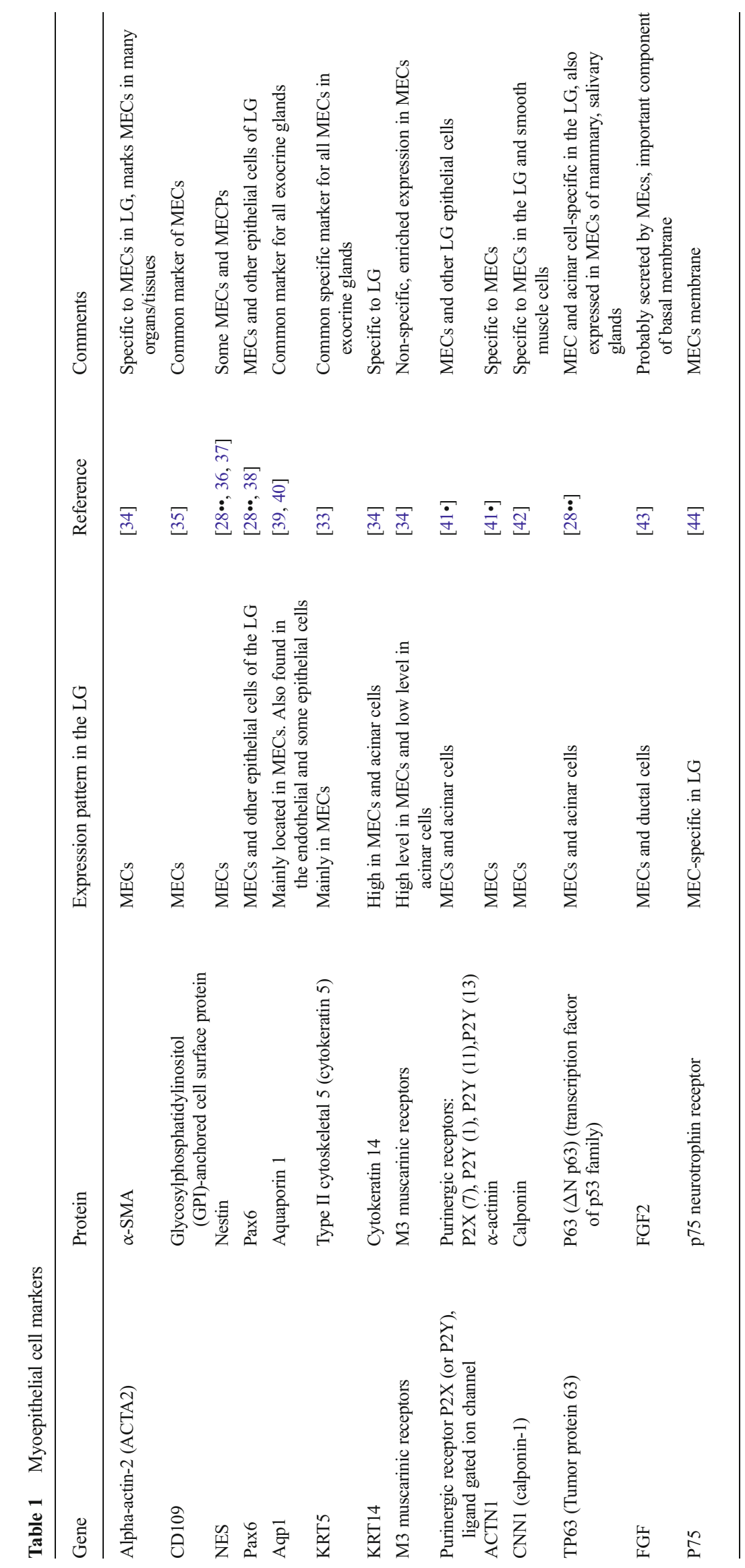




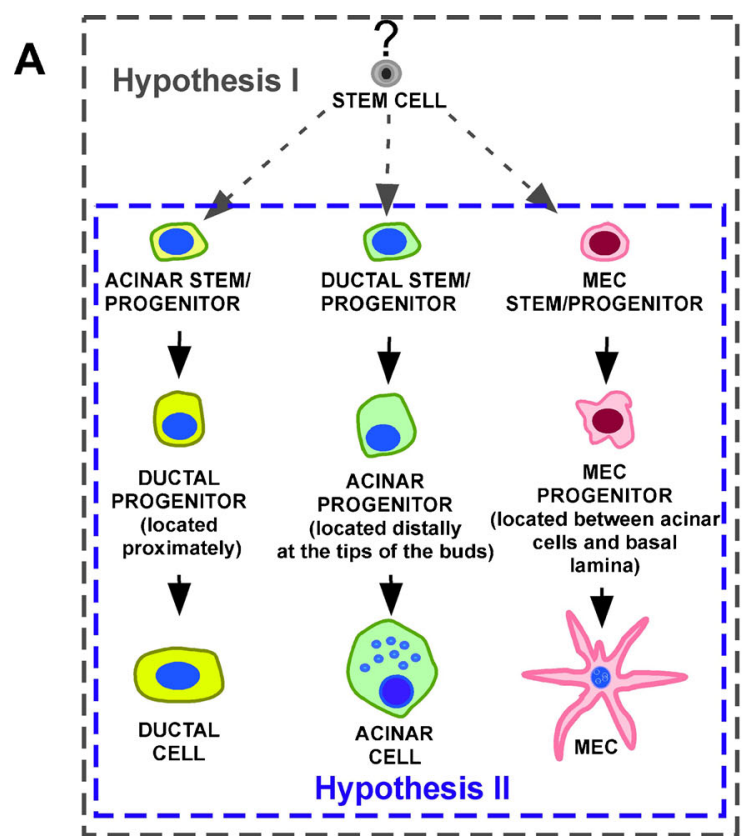

Fig. 3 Lacrimal gland epithelial cell lineage(s). Illustration of the three main hypotheses in cell lineage hierarchy in the LG. (a) Hypothesis I: slow cycling LG stem cell produce a common progenitor that gives rise to all LG lineages, epithelial (acinar and ductal) and myoepithelial (MEC). Hypothesis II: The LG has lineage-restricted stem/progenitor cells that give rise to specific cell types within each lineage. (b) Hypothesis III: This

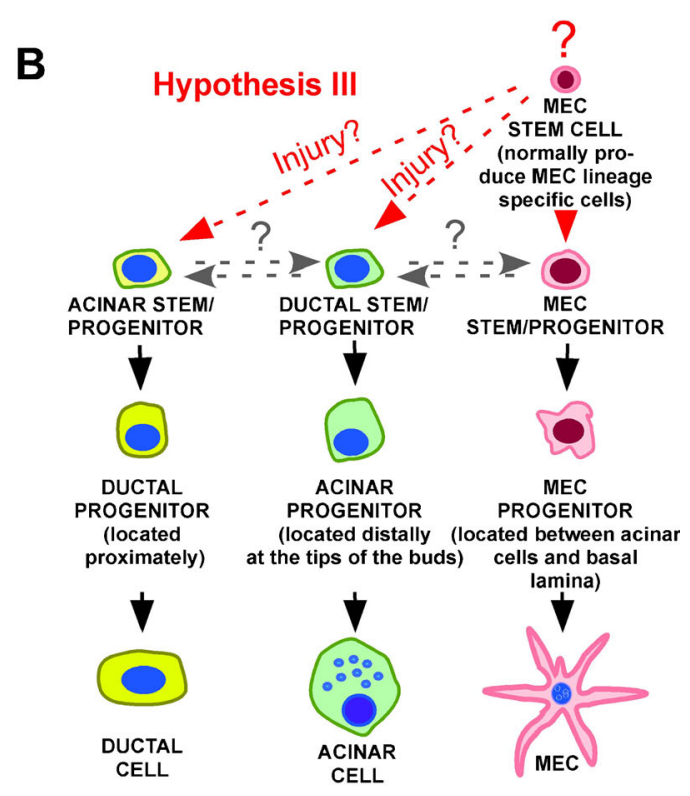

hypothesis suggests that multipotent stem/progenitor cells exist in one of the LG cell lineages. Based on reported plasticity of MECs, MEC lineage may likely contain multipotent stem-like cells that can restore all epithelial lineages upon LG injury. Dashed arrows label unknown connections and straight arrows reported connections

roles for MECs in these processes [88]. The position of MECs between the LG acinar epithelial cells and the basal membrane implies that MECs are an important part of the epithelialmesenchymal communication that often occurs through the extracellular matrix (ECM). In addition, MECs express receptors for neurotransmitters, suggesting that these cells are responsive for neurostimulation that induces secretion of lacrimal glad fluid [34]. In the lacrimal gland, MECs and acinar cells express $\mathrm{M}_{3}$ muscarinic receptors. These muscarinic agonists activate $\mathrm{M}_{3}$ receptors on acinar cells to stimulate lacrimal gland secretion and also cause contraction of MECs [89, 90].

The specific location of MECs in the LG at the periphery of secretory acini suggests a role for these cells in the maintenance of normal LG structure. However nothing is known about this function of the MECs in the LG. In contrast, MECs in mammary glands play an essential role in the control of mammary epithelium polarity [91]. Mammary gland luminal epithelial cells cultured in collagen-I gel formed acini with reversed polarity. The addition of MECs to these cultures led to the formation of acini-like structures with the correct polarity. The basement membrane component laminin-1 could also substitute for normal MECs in reversing polarity in collagen-I gels [91]. This finding suggests that secretion of basal membranes by MECs play an essential role in the maintenance of acinar polarity. In many tissues, including exocrine glands, the basal membrane is also an important intermittent component 
for epithelial-mesenchymal interaction and signaling. Similar to the mammary gland, basal membrane components of the LG such as laminin-1 or heparan sulfate are important regulators of growth factor signaling [92]. Binding growth factors (for example, fibroblast growth factors (FGFs)) to heparan sulfate creates morphogenetic gradients that control epithelial polarity and direction of LG epithelial growth/migration [92].

Fibroblast growth factors (FGFs) and their receptors (FGFRs), especially FGF10 and FGFR2b isoform play an important role in LG morphogenesis [20, 21, 92]. FGF10 is expressed by LG mesenchymal fibroblasts, released into ECM, and signals to the epithelial cells including MECs. In addition, MECs, especially those associated with the ductal epithelium of the LG, express FGF2, which is most likely released onto the basal membrane, since the basal membrane is positive for FGF2 [43]. FGF2 signals through FGFR1c isoform that is expressed by mesenchymal cells. Thus, MECs and the basal membrane are involved in the regulation of epithelial-mesenchymal crosstalk. Moreover, in response to various stimuli, FGFs can be released from the ECM as a soluble FGF-heparan sulfate complex to exert a specific role in response to injury and tissue remodeling.

\section{Conclusions}

MECs are proposed to be key cellular participants in LG morphogenesis, maintenance, and repair. However, little is known about the MEC lineage and the functional relationship between these cells and other LG cell types. Although many questions remain to be answered, significant technological advances are now providing the tools for progress in MEC research. Further analysis of MECs and other cell lineages of the LG are important for development of the new cell-based therapies, which hold the promise of restoring the function of damaged LG or glands with chronic disorders such as Sjögren's syndrome or other autoimmune disorders.

\section{Compliance with Ethics Guidelines}

Conflict of Interest Helen P. Makarenkova and Darlene A. Dartt declare that they have no conflict of interest.

Human and Animal Rights and Informed Consent All animal experiments performed by the authors in the publications cited in the current manuscript were approved by their institutions' animal care and use committee and followed ARVO guidelines for use of animals.

\section{References}

Papers of particular interest, published recently, have been highlighted as:

- Of importance

•- Of major importance

1. Gudjonsson T, Adriance MC, Sternlicht MD, Petersen OW, Bissell MJ. Myoepithelial cells: their origin and function in breast morphogenesis and neoplasia. J Mammary Gland Biol Neoplasia. 2005; 10 : 261-72.

2. Faraldo MM, Teuliere J, Deugnier MA, Taddei-De La Hosseraye I, Thiery JP, Glukhova MA. Myoepithelial cells in the control of mammary development and tumorigenesis: data from genetically modified mice. J Mammary Gland Biol Neoplasia. 2005;10:211-9.

3. Avci A, Gunhan O, Cakalagaoglu F, Gunal A, Celasun B. The cell with a thousand faces: detection of myoepithelial cells and their contributions in the cytological diagnosis of salivary gland tumors. Diagn Cytopathol. 2012;40:220-7.

4. Abe J, Sugita A, Hamasaki M, et al. Scanning electron microscopic observations of the myoepithelial cells of normal and contracting status in the rat harderian gland. Kurume Med J. 1981;28:103-12.

5. Raubenheimer EJ. The myoepithelial cell: embryology, function, and proliferative aspects. Crit Rev Clin Lab Sci. 1987;25:161-93.

6. Schon M, Benwood J, O'Connell-Willstaedt T, Rheinwald JG. Human sweat gland myoepithelial cells express a unique set of cytokeratins and reveal the potential for alternative epithelial and mesenchymal differentiation states in culture. J Cell Sci. 1999;112(Pt 12):1925-36.

7. Dartt DA. Neural regulation of lacrimal gland secretory processes: relevance in dry eye diseases. Prog Retin Eye Res. 2009;28:15577.

8. Wang YL, Tan Y, Satoh Y, Ono K. Morphological changes of myoepithelial cells of mouse lacrimal glands during postnatal development. Histol Histopathol. 1995;10:821-7.

9. Leeson TS, Leeson CR. Myoepithelial cells in the exorbital lacrimal and parotid glands of the rat in frozen-etched replicas. Am J Anat. 1971;132:133-45.

10. Beha G, Sarli G, Brunetti B, Sassi F, Ferrara D, Benazzi C. Morphology of the myoepithelial cell: immunohistochemical characterization from resting to motile phase. Sci World J. 2012;2012: 252034.

11. Vidi PA, Bissell MJ, Lelievre SA. Three-dimensional culture of human breast epithelial cells: the how and the why. Methods Mol Biol. 2012;945:193-219.

12. Beha G, Sarli G, Brunetti B, Sassi F, Ferrara D, Benazzi C. Morphology of the myoepithelial cell: immunohistochemical characterization from resting to motile phase. ScientificWorldJournal. 2012;2012:252034.

13. Rios JD, Horikawa Y, Chen LL, et al. Age-dependent alterations in mouse exorbital lacrimal gland structure, innervation and secretory response. Exp Eye Res. 2005;80:477-91.

14. de la Cuadra-Blanco C, Peces-Pena MD, Merida-Velasco JR. Morphogenesis of the human lacrimal gland. J Anat. 2003;203: 531-6.

15. Yoshino K, Tseng SC, Pflugfelder SC. Substrate modulation of morphology, growth, and tear protein production by cultured human lacrimal gland epithelial cells. Exp Cell Res. 1995;220:138-51.

16. Carella G, Castelli C. Study of the development of the microvascularization of the human lacrimal gland. Ann Ottalmol Clin Ocul. 1968;94:952-95.

17. Tripathi BJ, Tripathi RC. Evidence for the neuroectodermal origin of the human lacrimal gland. Invest Ophthalmol Vis Sci. 1990;31: 393-5. 
18. Ortiz-Delgado JB, Darias MJ, Canavate JP, Yufera M, Sarasquete C. Organogenesis of the digestive tract in the white seabream, Diplodus sargus. Histological and histochemical approaches. Histol Histopathol. 2003;18:1141-54.

19. Jimenez-Rojo L, Granchi Z, Graf D, Mitsiadis TA. Stem cell fate determination during development and regeneration of ectodermal organs. Front Physiol. 2012;3:107.

20. Govindarajan V, Ito M, Makarenkova HP, Lang RA, Overbeek PA. Endogenous and ectopic gland induction by FGF-10. Dev Biol. 2000;225:188-200.

21. Makarenkova HP, Ito M, Govindarajan V, et al. FGF10 is an inducer and Pax6 a competence factor for lacrimal gland development. Development. 2000;127:2563-72.

22. Jaskoll T, Zhou YM, Chai Y, et al. Embryonic submandibular gland morphogenesis: stage-specific protein localization of FGFs, BMPs, Pax6 and Pax9 in normal mice and abnormal SMG phenotypes in FgfR2-IIIc(+/Delta), BMP7(-/-) and Pax6(-/-) mice. Cells Tissues Organs. 2002;170:83-98.

23. Wakusawa $\mathrm{S}$. The development of the arterial system of the mouse eye. Nihon Ganka Gakkai Zasshi. 1968;72:1803-28.

24. Wiwatwongwana D, Berean KW, Dolman PJ, Rootman J, White VA. Unusual carcinomas of the lacrimal gland: epithelialmyoepithelial carcinoma and myoepithelial carcinoma. Arch Ophthalmol. 2009;127:1054-6.

25. Wilk CM, Vigneswaran N, Heese A, Hornstein OP, Naumann GO. Immunohistochemical characterization of epithelial cells in human lacrimal glands. II. Inflammatory and neoplastic lesions of lacrimal glands. Graefes Arch Clin Exp Ophthalmol. 1990;228:65-72.

26. Singh G, Sharma MC, Agarwal S, et al. Epithelial-myoepithelial carcinoma of the lacrimal gland: a rare case. Ann Diagn Pathol. 2011;16:292-7.

27. Rabade NR, Goel NA. Clear cell myoepithelial carcinoma ex pleomorphic adenoma. Indian J Pathol Microbiol. 2014;57:456-9.

28.• Shatos MA, Haugaard-Kedstrom L, Hodges RR, Dartt DA. Isolation and characterization of progenitor cells in uninjured, adult rat lacrimal gland. Invest Ophthalmol Vis Sci. 2012. This important article reports that in the intact LGs, myoepithelial cells (MECs) express the stem cell markers. Isolated and cultured MECs could differentiate into different cell lineages in suggesting the presence of multipotent stem/progenitor cells within MEC lineage.

29. Martin CL, Munnell J, Kaswan R. Normal ultrastructure and histochemical characteristics of canine lacrimal glands. Am J Vet Res. 1988;49:1566-72.

30. Cripps MM, Bromberg BB, Bennett DJ, Welch MH. Structure and function of non-enzymatically dissociated lacrimal gland acini. Curr Eye Res. 1991;10:1075-80.

31. Ding $\mathrm{C}$, MacVeigh $\mathrm{M}$, Pidgeon $\mathrm{M}$, et al. Unique ultrastructure of exorbital lacrimal glands in male NOD and BALB/c mice. Curr Eye Res. 2006;31:13-22.

32. Leoncini $\mathrm{P}$, Cintorino $\mathrm{M}$, Vindigni $\mathrm{C}$, et al. Distribution of cytoskeletal and contractile proteins in normal and tumour bearing salivary and lacrimal glands. Virchows Arch A Pathol Anat Histopathol. 1988;412:329-37.

33. Vigneswaran N, Wilk CM, Heese A, Hornstein OP, Naumann GO. Immunohistochemical characterization of epithelial cells in human lacrimal glands. I. Normal major and accessory lacrimal glands. Graefes Arch Clin Exp Ophthalmol. 1990;228:58-64.

34. Lemullois M, Rossignol B, Mauduit P. Immunolocalization of myoepithelial cells in isolated acini of rat exorbital lacrimal gland: cellular distribution of muscarinic receptors. Biol Cell. 1996;86: 175-81.

35. Hasegawa M, Hagiwara S, Sato T, et al. CD109, a new marker for myoepithelial cells of mammary, salivary, and lacrimal glands and prostate basal cells. Pathol Int. 2007;57:245-50.
36. Zoukhri D, Fix A, Alroy J, Kublin CL. Mechanisms of murine lacrimal gland repair after experimentally induced inflammation. Invest Ophthalmol Vis Sci. 2008;49:4399-406.

37. You S, Kublin CL, Avidan O, Miyasaki D, Zoukhri D. Isolation and propagation of mesenchymal stem cells from the lacrimal gland. Invest Ophthalmol Vis Sci. 2011;52:2087-94.

38. Voronov D, Gromova A, Liu D, et al. Transcription factors Runx 1 to 3 are expressed in the lacrimal gland epithelium and are involved in regulation of gland morphogenesis and regeneration. Invest Ophthalmol Vis Sci. 2013;54:3115-25.

39. Hayashi T. Dysfunction of lacrimal and salivary glands in Sjogren's syndrome: nonimmunologic injury in preinflammatory phase and mouse model. J Biomed Biotechnol. 2011;2011:407031.

40. Beroukas D, Hiscock J, Gannon BJ, Jonsson R, Gordon TP, Waterman SA. Selective down-regulation of aquaporin-1 in salivary glands in primary Sjogren's syndrome. Lab Invest. 2002;82: 1547-52.

41. Ohtomo K, Shatos MA, Vrouvlianis J, Li D, Hodges RR, Dartt DA. Increase of intracellular $\mathrm{Ca} 2+$ by purinergic receptors in cultured rat lacrimal gland myoepithelial cells. Invest Ophthalmol Vis Sci. 2011;52:9503-15. This article reports a method of MECs isolation MECs from rat lacrimal glands, and shows that MECs express P2X(7), P2Y(1), P2Y(11), and P2Y(13) purinergic receptors.

42. Hirayama M, Ogawa M, Oshima M, et al. Functional lacrimal gland regeneration by transplantation of a bioengineered organ germ. Nat Commun. 2013;4:2497.

43. Schechter J, Wallace M, Carey J, Chang N, Trousdale M, Wood R. Corneal insult affects the production and distribution of FGF-2 within the lacrimal gland. Exp Eye Res. 2000;70:777-84.

44. Ghinelli E, Johansson J, Rios JD, et al. Presence and localization of neurotrophins and neurotrophin receptors in rat lacrimal gland. Invest Ophthalmol Vis Sci. 2003;44:3352-7.

45. Vanaken H, Vercaeren I, Claessens F, et al. Primary rat lacrimal cells undergo acinar-like morphogenesis on reconstituted basement membrane and express secretory component under androgen stimulation. Exp Cell Res. 1998;238:377-88.

46. Espinosa Los de Monteros A, Millan MY, Ordas J, Carrasco L, Reymundo C, Martin Las de Mulas J. Immunolocalization of the smooth muscle-specific protein calponin in complex and mixed tumors of the mammary gland of the dog: assessment of the morphogenetic role of the myoepithelium. Vet Pathol. 2002;39:247-56.

47. Niki T, Pekny M, Hellemans K, et al. Class VI intermediate filament protein nestin is induced during activation of rat hepatic stellate cells. Hepatology. 1999;29:520-7.

48. Marappagounder D, Somasundaram I, Dorairaj S, Sankaran RJ. Differentiation of mesenchymal stem cells derived from human bone marrow and subcutaneous adipose tissue into pancreatic islet-like clusters in vitro. Cell Mol Biol Lett. 2013;18:75-88.

49. Di Bella A, Regoli M, Nicoletti C, Ermini L, Fonzi L, Bertelli E. An appraisal of intermediate filament expression in adult and developing pancreas: vimentin is expressed in alpha cells of rat and mouse embryos. J Histochem Cytochem. 2009;57:577-86.

50. Lloyd RV, Hardin H, Montemayor-Garcia C, et al. Stem cells and cancer stem-like cells in endocrine tissues. Endocr Pathol. 2013;24: $1-10$.

51. Lemullois M, Rossignol B, Mauduit P. Immunolocalization of myoepithelial cells in isolated acini of rat exorbital lacrimal gland: cellular distribution of muscarinic receptors. Biol Cell. 1996;86: $175-81$.

52. Laurikkala J, Mikkola ML, James M, Tummers M, Mills AA, Thesleff I. p63 regulates multiple signalling pathways required for ectodermal organogenesis and differentiation. Development. 2006;133:1553-63. 
53. Arason AJ, Jonsdottir HR, Halldorsson S, et al. deltaNp63 has a role in maintaining epithelial integrity in airway epithelium. PLoS ONE. 2014;9:e88683.

54. Koster MI, Marinari B, Payne AS, Kantaputra PN, Costanzo A, Roop DR. DeltaNp63 knockdown mice: a mouse model for AEC syndrome. Am J Med Genet A. 2009;149A:1942-7.

55. Medawar A, Virolle T, Rostagno P, et al. DeltaNp63 is essential for epidermal commitment of embryonic stem cells. PLoS ONE. 2008;3:e3441

56. Barbareschi M, Pecciarini L, Cangi MG, et al. p63, a p53 homologue, is a selective nuclear marker of myoepithelial cells of the human breast. Am J Surg Pathol. 2001;25:1054-60.

57. Bizet AA, Liu K, Tran-Khanh N, et al. The TGF-beta co-receptor, CD109, promotes internalization and degradation of TGF-beta receptors. Biochim Biophys Acta. 1813;2011:742-53.

58. Silva-Vargas V, Doetsch F. A new twist for neurotrophins: endothelial-derived NT-3 mediates adult neural stem cell quiescence. Neuron. 2014;83:507-9.

59. Trounson A, Pebay A. A role for neurotrophins in embryonic stem cell growth. Dev Cell. 2006;10:158-9.

60. Pyle AD, Lock LF, Donovan PJ. Neurotrophins mediate human embryonic stem cell survival. Nat Biotechnol. 2006;24:344-50.

61. von Bartheld CS. Neurotrophins in the developing and regenerating visual system. Histol Histopathol. 1998;13:437-59.

62. Vicario-Abejon C, Johe KK, Hazel TG, Collazo D, McKay RD. Functions of basic fibroblast growth factor and neurotrophins in the differentiation of hippocampal neurons. Neuron. 1995;15:105-14.

63. Schrader S, Liu L, Kasper K, Geerling G. Generation of two- and three-dimentional lacrimal gland constructs. In: Brewitt $\mathrm{H}$, editor. Research projects in dry eye syndrome. Basel, Switzerland: Reinhardt Druck; 2010. p. 49-56.

64. You S, Tariq A, Kublin CL, Zoukhri D. Detection of BrdU-label retaining cells in the lacrimal gland: implications for tissue repair. Cell Tissue Res. 2011;346:317-26.

65. Meinhardt A, Spicher A, Roehrich ME, Glauche I, Vogt P, Vassalli G. Immunohistochemical and flow cytometric analysis of long-term label-retaining cells in the adult heart. Stem Cells Dev. 2010;20:211-22.

66. Liu Z, Martin LJ. The adult neural stem and progenitor cell niche is altered in amyotrophic lateral sclerosis mouse brain. J Comp Neurol. 2006;497:468-88

67. Prockop DJ. Repair of tissues by adult stem/progenitor cells (MSCs): controversies, myths, and changing paradigms. Mol Ther. 2009;17:939-46.

68. Villadsen R. In search of a stem cell hierarchy in the human breast and its relevance to breast cancer evolution. APMIS. 2005;113:903-21.

69. Dawn B, Bolli R. Adult bone marrow-derived cells: regenerative potential, plasticity, and tissue commitment. Basic Res Cardiol. 2005;100:494-503.

70. Bajpai VK, Mistriotis P, Andreadis ST. Clonal multipotency and effect of long-term in vitro expansion on differentiation potential of human hair follicle derived mesenchymal stem cells. Stem Cell Res. 2011;8:74-84.

71. Rohmann E, Brunner HG, Kayserili H, et al. Mutations in different components of FGF signaling in LADD syndrome. Nat Genet. 2006;38:414-7.

72. Alenzi FQ, Lotfy M, Tamimi WG, Wyse RK. Review: stem cells and gene therapy. Lab Hematol. 2010;16:53-73.

73. Harada H, Ohshima H. New perspectives on tooth development and the dental stem cell niche. Arch Histol Cytol. 2004;67:1-11.

74. Schlotzer-Schrehardt U, Dietrich T, Saito K, et al. Characterization of extracellular matrix components in the limbal epithelial stem cell compartment. Exp Eye Res. 2007;85:845-60.
75. Singh G, Sharma MC, Agarwal S, et al. Epithelial-myoepithelial carcinoma of the lacrimal gland: a rare case. Ann Diagn Pathol. 2012;16:292-7.

76. Moret A, Tabareau-Delalande F, Joly A, de Muret A, Goga D, Laure B. Myoepithelial carcinoma of the lacrimal gland. Rev Stomatol Chir Maxillofac Chir Orale. 2014;115:172-7.

77. Li WC, Rukstalis JM, Nishimura W, et al. Activation of pancreaticduct-derived progenitor cells during pancreas regeneration in adult rats. J Cell Sci. 2010;123:2792-802.

78. Burgess KL, Dardick I, Cummins MM, Burford-Mason AP, Bassett $\mathrm{R}$, Brown DH. Myoepithelial cells actively proliferate during atrophy of rat parotid gland. Oral Surg Oral Med Oral Pathol Oral Radiol Endod. 1996;82:674-80.

79. Lombaert IM, Knox SM, Hoffman MP. Salivary gland progenitor cell biology provides a rationale for therapeutic salivary gland regeneration. Oral Dis. 2011;17:445-9.

80. Smith GH. Mammary stem cells come of age, prospectively. Trends Mol Med. 2006;12:287-9.

81. Zoukhri D, Fix A, Alroy J, Kublin CL. Mechanisms of murine lacrimal gland repair after experimentally induced inflammation. Invest Ophthalmol Vis Sci. 2008;49:4399-406.

82. Shatos MA, Haugaard-Kedstrom L, Hodges RR, Dartt DA. Isolation and characterization of progenitor cells in uninjured, adult rat lacrimal gland. Invest Ophthalmol Vis Sci. 2012;53:2749-59.

83. Burgess KL, Dardick I, Cummins MM, Burford-Mason AP, Bassett R, Brown DH. Myoepithelial cells actively proliferate during atrophy of rat parotid gland. Oral Surg Oral Med Oral Pathol Oral Radiol Endod. 1996;82:674-80.

84. Ohtomo K, Shatos MA, Vrouvlianis J, Li D, Hodges RR, Dartt DA. Increase of intracellular $\mathrm{Ca} 2+$ by purinergic receptors in cultured rat lacrimal gland myoepithelial cells. Invest Ophthalmol Vis Sci. 2011;52:9503-15.

85. Tiwari S, Ali MJ, Vemuganti GK. Human lacrimal gland regeneration: Perspectives and review of literature. Saudi J Ophthalmol. 2014;28:12-8. This review article gives an overview of the efforts in lacrimal gland regeneration and examines the past and ongoing research in cell based therapies in animals as well as human lacrimal gland cultures.

86. Tiwari S, Ali MJ, Balla MM, et al. Establishing human lacrimal gland cultures with secretory function. PLoS ONE. 2012;7:e29458.

87. Baek H, Noh YH, Lee JH, Yeon SI, Jeong J, Kwon H. Autonomous isolation, long-term culture and differentiation potential of adult salivary gland-derived stem/progenitor cells. J Tissue Eng Regen Med. 2014;8:717-27.

88. Edman MC, Marchelletta RR, Hamm-Alvarez SF. Lacrimal gland overview. In: Dartt DA, Bex P, D’Amore P, Dana R, Mcloon L, Niederkor J, editors. Ocular Perifery and Disorders. San Diego, USA: Elsevier Ltd; 2011. p. 68-73.

89. Mitchelson F. Muscarinic receptor agonists and antagonists: effects on ocular function. Handb Exp Pharmacol. 2012: 263-98.

90. Nakamura M, Tada Y, Akaishi T, Nakata K. M3 muscarinic receptor mediates regulation of protein secretion in rabbit lacrimal gland. Curr Eye Res. 1997;16:614-9.

91. Gudjonsson T, Ronnov-Jessen L, Villadsen R, Rank F, Bissell MJ, Petersen OW. Normal and tumor-derived myoepithelial cells differ in their ability to interact with luminal breast epithelial cells for polarity and basement membrane deposition. J Cell Sci. 2002;115:39-50.

92. Makarenkova HP, Hoffman MP, Beenken A, et al. Differential interactions of FGFs with heparan sulfate control gradient formation and branching morphogenesis. Sci Signal. 2009;2:ra55. 